\title{
Lockdowns and the US Unemployment Crisis
}

\author{
Christian Dreger ${ }^{1} \cdot$ Daniel Gros $^{2}$ (D)
}

Received: 22 January 2021 / Accepted: 3 August 2021 / Published online: 11 October 2021

(c) The Author(s), under exclusive licence to Springer Nature Switzerland AG 2021

\begin{abstract}
The Covid-19 pandemic led to an unprecedented decline of economic activity at the globe scale. To slow down the spread of the virus, most governments reacted with various measures of social distancing, such as mobility controls, business and school closures, etc. We investigate the short-term impact of social distancing measures on the US labour market, using a panel threshold model with high frequency (weekly) data on unemployment across US states allowing for heteroscedasticity. Labour is a key input in production, and thus a good proxy for the state of the economy. We find that changes in the restrictiveness of mandated social distancing, as measured by the Oxford Stringency Index, exert a strong impact on unemployment. The bulk of the reaction of unemployment to a change in the social distancing restrictions does not arise immediately, but with a delay of 2-4 weeks. In addition, the impact is asymmetric. If the policies switch to tighter regulations, the increase in unemployment is quicker and higher in absolute value than a decrease after relaxation. The state of the pandemic, proxied by the number of new infections and fatalities, constitutes only a marginal factor.
\end{abstract}

Keywords Corona pandemic $\cdot$ Lockdown and unemployment $\cdot$ Policy response

JEL Classification $\mathrm{E} 00 \cdot \mathrm{I} 18 \cdot \mathrm{O} 11$

\section{Introduction}

The Covid-19 pandemic has led to unprecedented economic decline. Since February 2020, policymakers around the globe have introduced several emergency measures such as social distancing and the wearing of masks, restrictions to mobility and travel and shutting down large parts of the economy, including firms, workplaces and schools. The aim to slow down

This article is part of the Topical Collection on Economics of COVID-19

Daniel Gros

danielg@ceps.eu

Christian Dreger

cdreger@europa-uni.de

1 European University, Viadrina Frankfurt, Oder, Germany

2 Centre for European Policy Studies (CEPS), Brussels, Belgium 
the spread of the virus (flatten the curve) initially led to the harsh restrictions (lockdown). During the summer period, many restrictions were lifted or relaxed, only to be reinstated when infections surged again during autumn and winter. The lockdown has been associated with a deep economic recession. Following Barro et al. (2020), the losses in output and consumption attributed to the current virus exceed those of the Spanish flu, even under conservative assumptions. The key question for policymakers is how to manage the tradeoff between the spread of the virus and the severity of the lockdown. Dealing with this trade-off is a major challenge under pandemic conditions (Eichenbaum et al. 2020).

The pandemic shifted both the aggregated supply and demand curve of the economy. On the supply side, infections and lockdowns worsened labour supply and productivity. On the demand side, layoffs and income losses (because of morbidity, quarantines, and unemployment) lowered household consumption and firms' investment. For example, more than one half of the participants surveyed reported substantial income and wealth losses (Coibion et al. 2020). Large drops in consumption, especially in travel and clothing, are also involved. The high uncertainty with respect to the path, duration and impact of the pandemic might create downward spirals that dampen business and consumer confidence, with further job losses due to the anticipation of lower future demand. Higher credit default and non-performing loans might contribute to tighter lending standards. Guerrieri et al. (2020) argue that supply shocks associated with the Covid-19 pandemic are amplified by changes in aggregate demand, especially shutdowns, layoffs and the exit of firms.

The appropriate design of policies is of critical importance, as massive losses can be involved. However, empirical evidence on the economic impact of lockdown policies is rather limited. Several studies have discussed the impact of non-pharmaceutical interventions (NPI) on the evolution of the pandemic, the latter proxied by the growth rate of infections in OECD member states (Pozo et al. 2020) or the decline in the virus reproduction rates (Brauner et al. 2020). Overall, the interventions are found to be successful in flattening the infection curve, to a more or less extent. Hsiang et al. (2020) argue that the interventions dampened the contagion, to the order of 61 million Covid-19 cases in six major countries (China, South Korea, Italy, Iran, France, and the US).

We provide new evidence on the short run impact of social distancing measures on the local economy proxied by US state level unemployment. To ensure a high number of observations in a rather short period of the pandemic, high frequency business indicators are needed. Although some popular indicators such as trade volumes and electricity consumption have been reported, they cover only partial aspects of economic activities. Unemployment claims and rates are the only comprehensive variables at the short run (weekly) frequency. As 55 weeks and 51 states (including the District of Columbia) are involved, empirical evidence can be based on more than 2800 observations.

The empirical evidence presented here is based on panel models with state specific thresholds. The results point to a strong and quick impact of the lockdown on unemployment. From the variety of measures, closures of schools and working places seem to be most critical for the economy. The bulk of the reaction of unemployment to a change in the social distancing restrictions is observed with a delay of 2-4 weeks. The evolution of unemployment is highly asymmetric. If the government switches to tighter regulations, the increase in unemployment is higher in absolute value than a decrease after a relaxation. Hence, the decline in unemployment towards the end of the sample cannot be explained in terms of regulation easing. Controls representing the spread of the disease, such as the number of new infections and fatalities exert some impact, but their role is minor.

The next section provides a summary of existing studies of the economic impact of social distancing. Section 2 offers a small model of the impact of lockdowns on the labour 
market. Section 3 presents the broad trends of the US labour market during the 'Great Lock-down'. Section 4 explains the Oxford index of restrictiveness used in the empirical analysis and Sect. 5 presents the main results from our panel estimates allowing for asymmetric effects, using data for US states. More than 55 weekly observations are available per state. Section 6 concludes.

\section{Studies of the Economic Impact of Social Distancing}

A large number of studies has already investigated the impact of the corona lockdown on the economy, although mostly from a model-specific angle concentrating on the early phase of the pandemic.

Bodenstein et al. (2020) stress that the absence of social distancing may amplify the costs of the pandemic over longer time intervals. To lower costs, social distancing should be skewed towards non-essential industries and professions that can be performed from home. Due to input-output linkages, however, even non-targeted industries can be affected. According to Getachew (2020), voluntary distancing is very important for both flattening the infection curve and limiting damage to the economy over the course of the pandemic. Laeven (2020) emphasises that producers of intermediates tend to be more affected by the crisis if they sell their output to industrial sectors restricted by social distancing.

Based on a computable general equilibrium (CGE) model, Walmsley et al. (2020) concluded that GDP in the US will fall by 15-23\% over a two year period, depending on the duration, the strength of the crisis and the availability of vaccines. Mandatory closures of businesses and partial reopenings are the most relevant factors influencing the results. Similarly, Mandel and Veetil (2020) estimated global losses of 23\% if many countries operate under a lockdown. Trade in intermediate inputs along global value chains might amplify the effects. By using a neural network approach calibrated for 8 large countries, Jena et al. (2021) found double-digit losses in GDP growth. Because of oversimplified assumptions, the simulation evidence should be probably interpreted as an upper bound. For example, markets are perfectly competitive and adjust instantaneously. Reductions in output are accompanied by a corresponding decline in wages and salaries as people become unemployed, with adverse effects on demand. In addition these simulations do not take into account the huge stimulus packages which have prevented a fall in disposable income from most households.

Based on costly disasters from the past, Ludvigson et al. (2020) have estimated the costs of the pandemic for the US. While past disasters were mostly locally concentrated and rather short-lived, the Covid-19 shock is modelled as a sequence of large disasters in a VAR environment. Even under the conservative scenario, the pandemic will lead to cumulative losses in industrial production of $20 \%$ and in employment in the services sector of $40 \%$, i.e. more than 55 million jobs are expected to be lost over the next 12 months. Therefore, massive reallocations of labour are inevitably involved. For New York, Gharehgozli et al. (2020) predicted a GDP drop of $25 \%$ in the first half after the outbreak of the crisis.

Chudik et al. (2020) specified a threshold global VAR model to quantify the potentially nonlinear macroeconomic effects of Covid-19. The relationship between output growth and uncertainty, proxied by excess volatility, is subject to threshold effects for both advanced and emerging countries. The Covid-19 shock is identified by the IMF forecast revisions of GDP growth. Results suggest that the pandemic caused a long-lasting decline in global output, although the effects tend to be unequal in different regions. While Asian countries are 
less affected, and boosted by the Chinese catch-up, the impacts are larger in the West. Due to strong interlinkages through trade, the findings call for a coordinated multi-country policy response to mitigate the effects of the pandemic.

Pagano et al. (2020) and Capelle-Blancard and Desroziers (2020) examine the effects of the pan-demic on the US stock market and highlight its differential impact on various sectors. Baker et al. (2020) show that uncertainty proxied by stock market volatility, newspaper-based uncertainty and subjective uncertainty in business expectation surveys rose sharply as the pandemic worsened.

Kok (2020) reports a negative relationship between GDP growth and stringency policy measures in a panel of 106 developed and developing countries. As GDP information is available only quarterly and with considerable delay, the time series dimension of such an analysis includes only $2-3$ observations per country.

With respect to the labour market, the fact that the pandemic has exacerbated pre-existing in-equalities has received most attention. Although employment losses are widespread, they are substantially larger in lower-paying occupations and industries. Individuals from disadvantaged groups, i.e. Hispanics, younger workers, those with lower levels of education and women have suffered larger job losses and decreases in hiring rates (Cortes and Forsythe 2020). This indicates that the economic burden of the corona crisis will mostly affect those people who are already in the most vulnerable financial situation (Gascon 2020). Job losses tend to be less pronounced for employees who can work remotely (Montenovo et al. 2020). By looking at high frequency state-level data, Baek et al. (2020) argue that orders to people to stay at home unless their work is deemed essential accounted for a substantial, but nonetheless minority share of the rise in unemployment claims.

By using real-time information on the number of vacancies and unemployment insurance claims, Forsythe et al. (2020) concluded that the US labour market deteriorated substantially but did so across the board, rather than more in states with shutdown orders. Therefore, individual state policies and own epidemiological situations have had only a moderate effect, see also Rojas et al. (2020). By contrast, Gupta et al. (2020) found a major role for state socialdistancing policies, in addition to the impact of the nationwide shock. There has been a broad retreat across almost all industries, whether they are seen to be essential or not. According to Katafuchi et al. (2021) non-legally binding policies can help to reduce the number of people going out, because many people fear psychological and stigma costs. Hence, self-constraint behaviour can reduce the infection risk in addition to harder lockdowns. Based on a survey of 5800 small businesses, Bartik et al (2020) reported large employment losses caused by the pandemic. Martin et al (2020) argued that low income households suffer more, as the virus worsens their job perspectives. However, policies like a broader coverage of unemployment insurance could be suitable to prevent an increase in poverty.

Most of the existing studies concentrate on the initial phase of the pandemic (first wave) and the associated harsh lockdown. In contrast to previous studies, our sample spans a period of substantial reversal of measures, which were eased during the summer and then re-imposed or tightened again later the year. In particular, we look at the time period during which many re-strictions were first loosened and then tightened again. Moreover, different dimensions of the lockdown are distinguished. 


\section{Modelling the Impact of a Lockdown on the Labour Market}

A lockdown can be expected to cause an increase in unemployment. Closing shops, schools, entertainment venues and forbidding meetings involving more than a small number of persons has adverse effects on both supply and demand (Guerrieri et al 2020 and Eichenbaum et al 2020). The decline in economic activity might be due to actual business closures, prohibitions or lower efficiency. Due to the lower output, employment will be reduced. This can be inferred, for example, from conditional (Hicks-type) labour demand equations, where labour input depends on the level of production (in addition to its own price (which, however, did not change much). The fall in employment is mirrored by a rise in (registered and non-registered) unemployment. Hence, standard models postulate a positive relationship between the degree of restrictiveness and unemployment.

More formally, aggregate output at each point in time, $t$, can be modelled as the sum of the output of many different goods, denoted by $y_{\mathrm{i}, \mathrm{t}}$ produced by competitive firms, employing labour, $n$, with a linear technology. Denoting the amount of labour employed in each firm by $n_{i, \mathrm{t}}$ we can thus determine total employment, $N_{\mathrm{t}}$, simply by the sum of employment over all firms:

$$
Y_{t}=\sum_{0}^{1} y_{i, t}=N_{t}=\sum_{0}^{1} n_{i, t}
$$

The firms are assumed to be distributed over the measure [0,1]. In this set-up overall employment is equivalent to aggregate output and can be influenced both by demand and supply restrictions: Some NPIs like closures of non-essential shops or restaurants reduce supply. School closures might also prevent workers, especially mothers, to attend to their jobs if they require a physical presence. The spread of the disease might also reduce demand for several services which in principle were not closed, like travel. Stay at home orders might be regarded as limiting the ability of consumers to spend.

We thus posit that NPIs prevent a set of measure $\Omega$ of workers to do their job:

$$
n_{i, t}=0, \quad \forall i \in \Omega
$$

The fear of contagion and some NPIs are assumed to affect the demand for a set $\Psi$ of goods, some of which might also have been affected by supply restrictions.

$$
y_{i, t}=0, \quad \forall i \in \Psi
$$

Total unemployment $u$ would then be given by the combination of both sets.

$$
u=1-\sum n_{i, t}, \quad \forall i \in \Omega \cup \Psi
$$

The number of infections and deaths used in the empirical analysis below are would be included in the set $\Psi$, whereas the set $\Omega$ is represented by the Oxford restrictiveness index. 


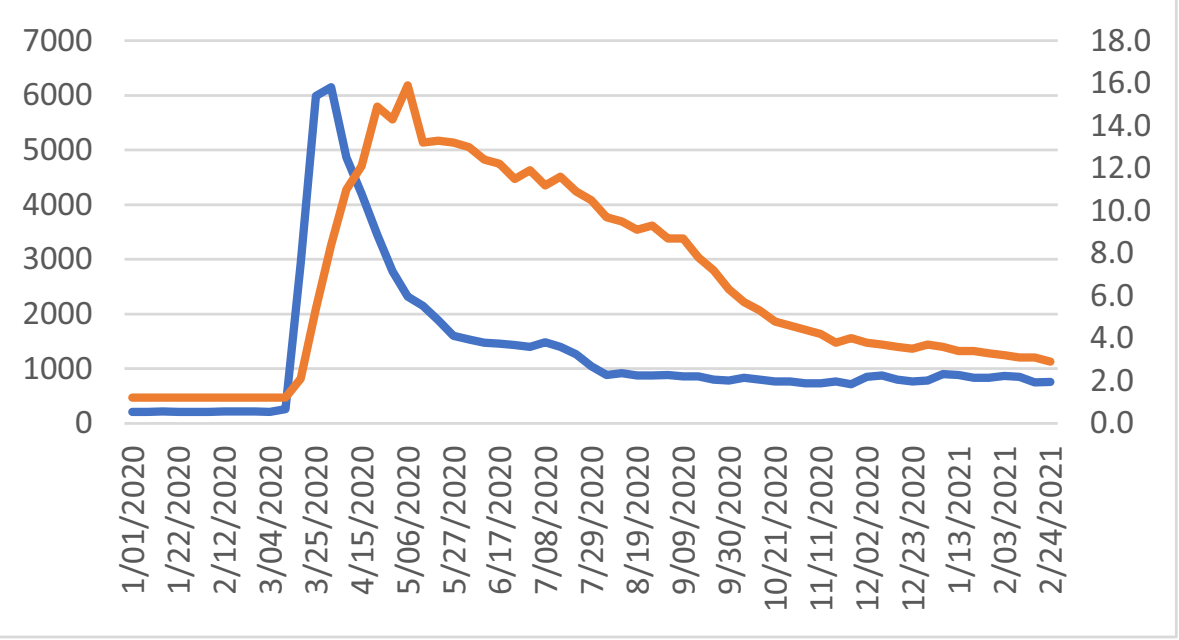

Fig. 1 Initial unemployment claims (IUC) and the Insured Unemployment Rate (IUR) during the lockdown. Source: Own elaborations on BLS data. Left hand axis initial unemployment claims (total for US) in thousands. Right hand axis: Insured unemployment rate

\section{Trends in US Labour Markets During the 'Great Lockdown'}

The corona crisis led to a sudden increase in US unemployment. While the insured unemployment rate (IUR) was at record lows just before the outbreak of the crisis, it shot up to almost $16 \%$ in April. Since then, unemployment has gradually fallen, but remains at more than double the pre-crisis value.

The IUR is equal to the number of people receiving unemployment insurance as a percentage of the labour force and reported at a weekly frequency. The measured IUR does not comove im-mediately one to one with the number of unemployment claims filed in the same week. This was particularly the case in the early phases of the crisis when the local unemployment offices were overwhelmed by the huge number of initial claims. Figure 1 illustrates how initial unemployment claims shot up immediately when major measures were taken, followed by a more gradual increase in the (insured) unemployment rate. Initial claims (IUC) might constitute a useful alternative measure of the state of the labour market (Cajner et al. 2020). Therefore, initial unemployment claims are also used for a robustness test. In terms of both the IUR and IUC one finds a similar pattern throughout the US: An initial sharp increase, followed by a gradual decline and then another uptick.

Within this overall pattern, the magnitudes differ substantially across states (Fig. 2). For in-stance, the largest increase in the unemployment rate, of almost $30 \%$ points, can be observed for Washington, followed by California, Vermont and Florida. In contrast, the labour markets in Utah and Wyoming showed higher resilience, with an increase of around $6 \%$ points. States with a high share of employment working in the tourism sector such as Nevada (25\%, due to the gaming industry) and Hawaii (20\%) experienced an above-average increase in unemployment. 


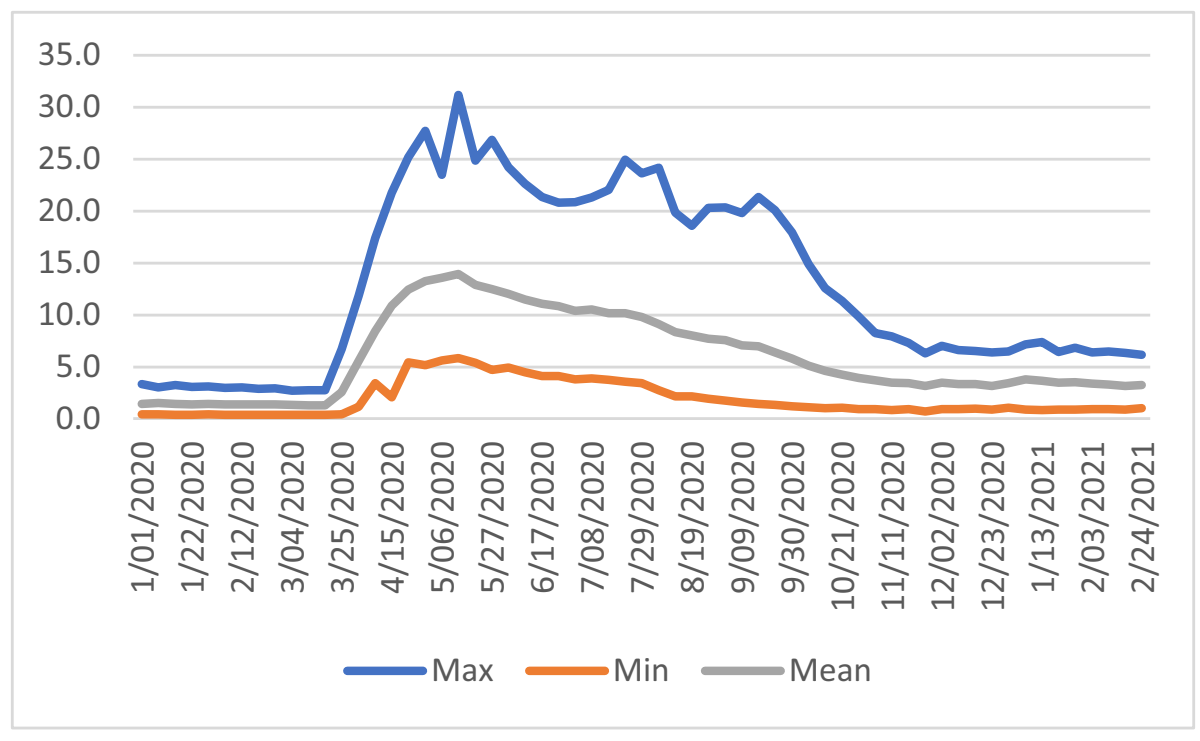

Fig. 2 Unemployment rates across States: Mean and dispersion. Source: Own elaborations on BLS data. The line 'Max' shows the value for the US State with the highest value for that week and similarly for 'Min'

\section{Measuring Policy Restrictions}

Several indicators are available to assess the scope of corona-related policies. The government response tracker developed by the Blavatnik School of Government, Oxford University, is the standard measure of policies to arrest the spread of the virus (Hale et al. 2020). It collects daily information on containment and closure practices, which is publicly available from various sources. ${ }^{1}$ The components of the Oxford index are rank scaled. Larger values represent a higher level of stringency of the respective policy but quantitative differences between two values can-not be interpreted (Table 1).

Each individual component is rescaled between 0 and 100. A composite indicator is constructed as the average of the individual components

$$
O X=\frac{1}{8} \sum_{i=1}^{8} O_{i}
$$

Due to their construction the indices vary between 0 and 100 . In principle, the individual series in the Oxford indicator can be aggregated in different ways. The advantage of (1) is that the simple average is easy to handle and allows for some averaging out of potential measurement errors on the individual components. With the exception

\footnotetext{
${ }^{1}$ One alternative to the Oxford indicator is the Google mobility index. It includes different aspects of mo-bility behaviour, such as visits to parks. For this paper, the information provided by the index is very limited, as seasonal patterns are involved. Compared to Feb 2020, the Google index shows an increase in mobility for the rest of the year, probably not because of relaxed restrictions but also due to warmer temperatures after winter.
} 
Table 1 Components of the Oxford indices

\begin{tabular}{ll}
\hline & Min/max \\
\hline School closures & $0 / 3$ \\
Working place closures & $0 / 3$ \\
Cancellation of public events & $0 / 2$ \\
Restrictions on gatherings & $0 / 4$ \\
Close of public transport & $0 / 2$ \\
Stay at home requirements & $0 / 3$ \\
Restrictions on internal movements & $0 / 2$ \\
International travel controls & $0 / 4$ \\
\hline
\end{tabular}

Dimensions of the Oxford stringency index. Min/Max column represents minimum and maximum values. Taken the closures of schools as an example, the values are 0 (no closure), 1 (closing recommended), 2 (only some types of schools, such as high schools) and 3 (all schools)

\begin{tabular}{lllllllll}
\hline & $O_{1}$ & $O_{2}$ & $O_{3}$ & $O_{4}$ & $O_{5}$ & $O_{6}$ & $O_{7}$ & $O_{8}$ \\
\hline$O_{1}$ & 1 & & & & & & & \\
$O_{2}$ & 0.69 & 1 & & & & & & \\
$O_{3}$ & 0.69 & 0.75 & 1 & & & & & \\
$O_{4}$ & 0.59 & 0.69 & 0.72 & 1 & & & & \\
$O_{5}$ & 0.35 & 0.40 & 0.33 & 0.35 & 1 & & & \\
$O_{6}$ & 0.54 & 0.62 & 0.58 & 0.54 & 0.26 & 1 & & \\
$O_{7}$ & 0.40 & 0.51 & 0.44 & 0.44 & 0.27 & 0.42 & 1 & \\
$O_{8}$ & 0.23 & 0.26 & 0.27 & 0.27 & 0.14 & 0.20 & 0.46 & 1 \\
\hline
\end{tabular}

Weekly data ranging from Feb 12, 2020 to Feb 24, 2021. Own calcula-

tions based on Hale et al. (2020)
Table 2 Correlation between Oxford components

of international travel controls, the correlation between the other components of the Oxford indicator is rather high, where the individual coefficients often exceed 0.6 , indicating both substantial co-movements, but also considerable differences (Table 2). Despite the fact that several restrictions have been gradually lifted, the stringency of the regulations is still at rather high levels. The standard deviation of the average indicator across US states oscillates between 10 and 15 points (compared to an indica-tor level between 40 and 60 points). There is thus substantial cross-sectional variation that can be exploited in a panel setting.

The US federal government has only limited direct control over the implementation of strategies to combat the crisis. Instead, many decisions are taken at the state, sometimes even at the local level. The overall policy response to the virus is displayed in Fig. 3, together with the maximum and minimum across the US states. Measures entered into force directly after the outbreak of the crisis and reached a peak in April. Since then, a slight downward trend is observed on aver-age. Stricter policies have been applied in Alaska, Idaho, Kentucky, Maryland and New Mexico, while Arkansas, Iowa, North and South Dakota and Utah switched to more liberal regulations. The least-stringent states, mostly in the Mid-West, had Republican governors (Hale et al. 2020). 


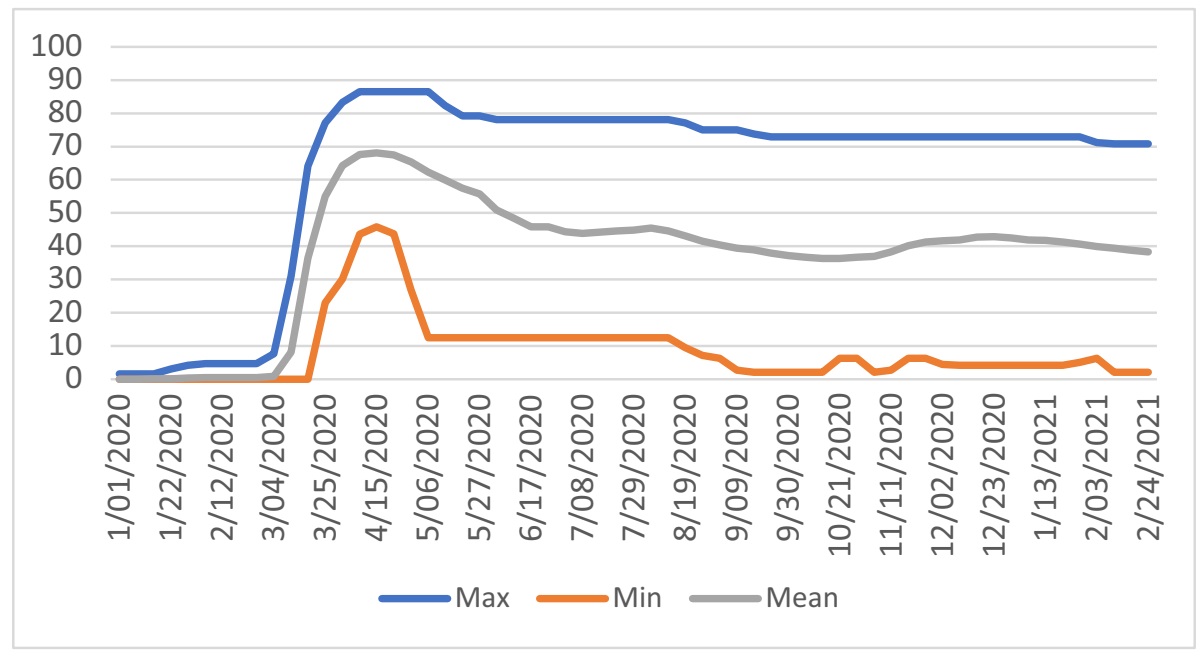

Fig. 3 Oxford stringency index for the US economy, mean and dispersion. Note: Mean of composite index (grey), minimum (min) and maximum (max) values across the US states. Index according to Hale et al. (2020)

\section{Panel Regressions with Asymmetric Effects}

Panel models with state fixed effects $(\alpha)$ are estimated for the 51 US states (including the District of Columbia) over the pandemic period, i.e., February 2020 to February 2021. Unemployment rates and initial claims are available at a weekly frequency from the BLS. Weekly Oxford indices are obtained by averaging daily values over the week. In total $51 \times 55=2803$ observations are available, implying a high number of degrees of freedom. To exclude potentially spurious regressions due to trending behaviour in the variables, the equation is expressed in first differences $(\Delta)$. As the unemployment reaction might not be immediate, a delay of up to 4 weeks is al-lowed. In addition, a threshold is introduced to capture an asymmetric unemployment response to the policy change. Hence, the slope parameters can be different, depending on whether policy is tightened or relaxed.

The spread of the virus is widely perceived to have an independent impact on the economy: News of higher infections can cause higher uncertainty or caution in certain areas of consumption expenditures (restaurant trips, travel, etc.), leading to an independent fall in labour demand or a rise in unemployment (Baker et al. 2020; Coibon et al. 2020). In order to account for this separate effect, we introduced as controls both the number of infections and deaths (relative to population) at the level of the individual states.

Overall, the unemployment rate $u$ is explained by the composite Oxford indicator $O$, its individ-ual components and corona-related controls for the spread of the disease i.e.

$$
\Delta u_{i t}=\alpha_{i, j}+\sum_{k=0}^{4} \beta_{j, k} \Delta O_{i, j, t-k}+\sum_{k=0}^{4} \gamma_{j, k} d_{i, j, t-k} \Delta O_{i, j, t-k} \sum_{k=0}^{4} \delta_{l, k} \Delta \text { corona }_{i, l, t-k}+\varepsilon_{i, j, t}
$$

The indices $i$ and $j$ denote the individual state and the number of the Oxford indicator $(\mathrm{i}=1 \ldots 51 ; \mathrm{j}=1 \ldots 8$ and 9 for the composite index), $t$ is time, $k$ the delay and $\epsilon$ the error term. The threshold is implemented through a binary variable $d$. It is equal to 1 if a policy becomes tighter and 0 otherwise. Hence, the impact is equal to $\beta_{\mathrm{jk}}+\gamma_{\mathrm{jk}}$ if the policy 
Table 3 Impact of NPIs on the labour market: composite Oxford indicator

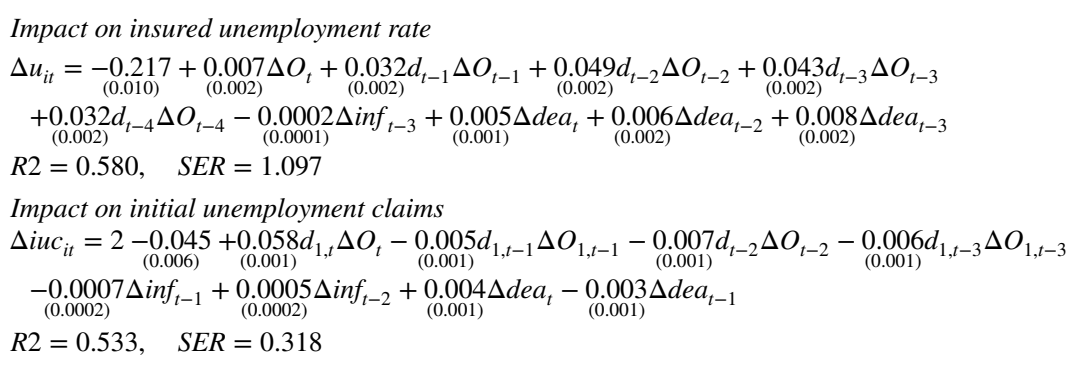

Panel model with fixed effects for the 51 US states (including District of Columbia) and cross section GLS weights to control for cross section heteroscedasticity, weekly data from Feb 12, 2020 to Feb 24, 2021. $I U R=$ Insured unemployment rate, $I U C=$ Initial unemployment claims (logs). Standard errors in parentheses below regression coefficients. The constant is the average of state level fixed effects. $O$ denotes the specific policy covered by the Oxford index, $d$ is equal to 1 if a policy is tightened and 0 otherwise, inf is the number of new infections and dea the number of deaths. $R 2$ adjusted coefficient of determination and SER the standard error of regression

$j$ became stricter $k$ periods ago. In case of no change or a policy relaxation, the coefficient is $\beta_{\mathrm{jk}}$. Corona controls $(l=1,2)$ refer to the number of infections and deaths associated with the pandemic. The results are shown in Table 3. To improve the readability of the results, only significant coefficients are shown. The starting point of the model evaluation is an over-parameterised model structure with many insignificant variables, due to multicollinearity. At each round of the subsequent iteration process, the least significant regressor is removed. The final specification includes only explanatories with $t$-values larger than 2 . Exactly the same equation is estimated using the same procedure with initial unemployment claims as the dependent. Cross section fixed effects are implemented (state-individual constant) and cross section weights allowing for heteroscedasticity are embedded. The two panels of Table 3 contain the results:

The results point to a clear impact of the lockdown on the course of unemployment, which is rapid and asymmetric.

In the case of the unemployment rate (upper panel of Table 3) a contemporaneous impact of a change in the Oxford restrictiveness indicator can be observed. If the policy is tightened (i.e., $d=1$ ) the impact continues until a lag of 4 . The sum of the point estimates not involving a tightening is equal to 0.007 , which would imply that a change in the aggregate Oxford index of one standard deviation (20 points) should be followed by a change in the unemployment rate of $0.14 \%$ points. However, the sum of the coefficients on tightening is equal to 0.16 , implying that a tightening of the same amount leads to an increase in unemployment which is a multiple of this value (3.2\% points of an increase in the Oxford Stringency Index of one standard deviation). If one considers the initial jump from 0 to 70 (the average degree of restrictiveness in March) the equation could explain an increase of almost to $10 \%$ points which is not far from the increase in the average unemployment rate recorded in Spring of 2020.

The result with initial unemployment claims as the dependent variable (lower panel of Table 3) show an immediate impact of the restrictions and a complete asymmetry in the sense that one finds significant coefficients only for tightening, not for a loosening of restrictions. This makes sense since the initial claims only measure firings, i.e. the outflow from the labour market. A loosening of restrictions should lead to more hiring, but should not 
necessarily have an impact on firings. A quite strong immediate response is followed with one lag by a further increase in claims, which then is partially reversed during the following few weeks (which implies that the number of new claims falls, but remains higher than before.. Increases in infections and deaths also have significant contemporaneous impact on unemployment claims, but the effect is mostly fully compensated one period later.

The different lag structures found for the unemployment rate and initial claims is also visible in the more gradual increase in the unemployment rate already documented in Fig. 1 and can be explained, inter alia, by the time needed to process initial claims. Only those accepted are then included in the unemployment numbers (Cajner et al. 2020). The impact of controls such as the number of new infections and the number of deaths has some impact on unemployment, but any effect dissipates quickly as the sum of the coefficients over all significant lags is zero.

Furthermore, we also estimated the same equation separately for each Oxford component listed in Table 1 . The results are reported in Table 4 in the annex. This strategy can provide some evidence on the appropriate design of policies from an economic point of view. Table 4 shows that school and working place closures are most critical for the economy. In addition, the results also confirm in all cases that the impact on unemployment is governed by substantial asymmetries. If the government switches to tighter regulations, the increase in unemployment is higher in absolute value than a decrease after a relaxation. Note that international flight controls show only a minor impact on the course of unemployment, probably due to the large domestic market in the US. Nakamura and Managi (2020) discuss the relevance of flight restrictions more generally at the global scale.

These results for individual social distancing restrictions also confirm that the state of the pan-demic has only a marginal impact, whether one adds as controls the number of new infections or the number of fatalities. Short time lags are also confirmed. As a rule, the reaction of unemployment to a changing economic environment is observed with a delay of about 2-4 weeks.

\section{Conclusions}

The Covid-19 pandemic led to an unprecedented recession and spike in unemployment as policy makers had to resort to lockdowns to limit the spread of the disease. This paper provides evidence on the impact of the lockdowns on labour markets in the US. We document considerable heterogeneity among individual states, both in terms of the labour market performance and the time path of the restrictions imposed.

We used panel threshold models accounting for heteroscedasticity, for US states and based on weekly data. To examine the robustness of the results, two labour market indicators are distinguished, the insured unemployment rate (IUR) and initial unemployment claims (IUC). The details of the policy responses to the pandemic are proxied by the different components of the Oxford stringency index. Again, these indicators (e.g. school closures, prohibitions on mass gatherings, etc.) shows considerable variation across the US states.

The impact of the policy measures on unemployment is rapid: the unemployment rate increases within 2-4 weeks of policy measures being taken and unemployment claims respond almost im-mediately. The impact is also highly asymmetric, as tightening measures are far more important than easing measures. 
Table 4 Impact of different NPIs on the labour market

Insured unemployment rate

School closures

$\Delta$ iur $_{i t}=\underset{(0.011)}{-0.132}+\underset{(0.001)}{0.019} \Delta O_{1,4 t-4}+\underset{(0.001)}{0.016 d_{1, t-1}} \Delta O_{1, t-1}+\underset{(0.001)}{0.028 d_{1, t-2}} \Delta O_{1, t-2}+\underset{(0.001)}{0.028 d_{1, t-3}} \Delta O_{1, t-3}+\underset{(0.002)}{0.009} \Delta d e a_{t-4}$ $R 2=0.526, \quad S E R=1.126$

Working place closures

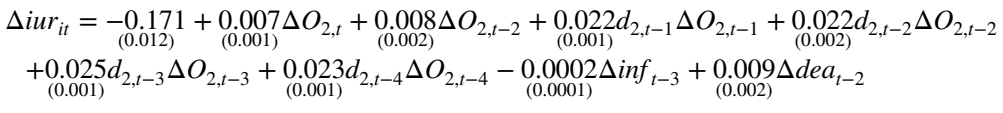

$R 2=0.490, \quad S E R=1.128$

Cancellation of public events

$\Delta$ iur $_{i t}=\underset{(0.012)}{-0.176}+\underset{(0.001)}{0.002 \Delta O_{3, t}}+\underset{(0.001)}{0.012 d_{3, t-1} \Delta O_{3, t-1}}+\underset{(0.001)}{0.023 d_{3, t-2} \Delta O_{3, t-2}}+\underset{(0.001)}{0.026 d_{3, t-3} \Delta O_{3, t-3}}$
$+\underset{(0.001)}{0.023 d_{3, t-4} \Delta O_{3, t-4}-\underset{(0.0001)}{0.0002} \Delta i n f_{t-4}}+\underset{(0.002)}{0.009 \Delta d e a_{t}}+\underset{(0.002)}{0.011} \Delta d e a_{t-2}+\underset{(0.002)}{0.010 \Delta d e a_{t-4}}$

$R 2=0.474, \quad S E R=1.158$

Restrictions on gatherings

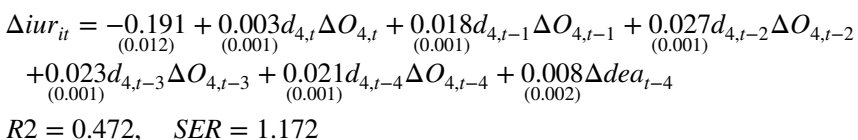

Close of public transport $\Delta$ iur $_{i t}=\underset{(0.013)}{-0.082}+\underset{(0.003)}{0.027 d_{5, t} \Delta O_{5, t}}+\underset{(0.003)}{0.040 d_{4, t-1} \Delta O_{4, t-1}}+\underset{(0.003)}{0.043 d_{4, t-2} \Delta O_{4, t-2}}$
$+\underset{(0.003)}{0.032 d_{4, t-3} \Delta O_{4, t-3}}+\underset{(0.003)}{0.014 d_{4, t-4} \Delta O_{4, t-4}}+\underset{(0.002)}{0.015 \Delta d e a_{t}}+\underset{(0.003)}{0.009} \Delta d e a_{t-2}$

$R 2=0297, \quad S E R=1.247$

Stay-at-home requirements

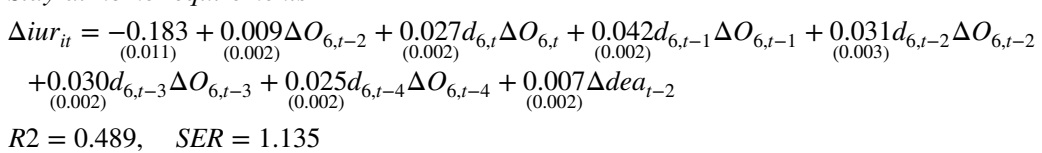

Restrictions on internal movement

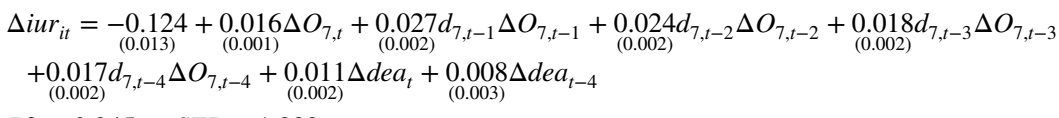

$R 2=0.345, \quad S E R=1.222$

International travel controls

$$
\begin{aligned}
& \Delta i u r_{i t}=\underset{(0.013)}{-0.033}+\underset{(0.004)}{0.038 d_{8, t}} \Delta O_{8, t}+\underset{(0.004)}{0.025 d_{8, t-1}} \Delta O_{8, t-1}+\underset{(0.004)}{0.023} d_{8, t-2} \Delta O_{8, t-2}+\underset{(0.004)}{0.019} d_{8, t-3} \Delta O_{8, t-3} \\
& +\underset{(0.002)}{0.018 \Delta \text { dea }_{t}}+\underset{(0.003)}{0.012 \Delta \text { dea }_{t-2}}+\underset{(0.003)}{0.009 \Delta \text { dea }_{t-4}}
\end{aligned}
$$

Initial unemployment claims

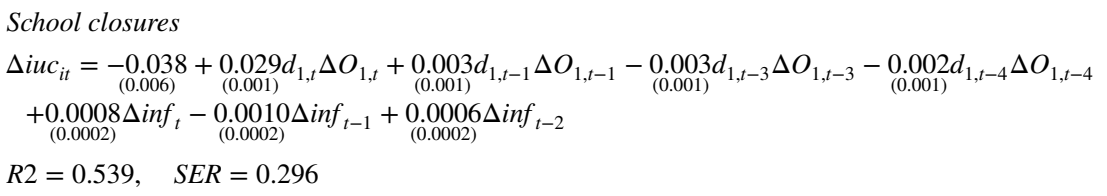


Table 4 (continued)

Initial unemployment claims

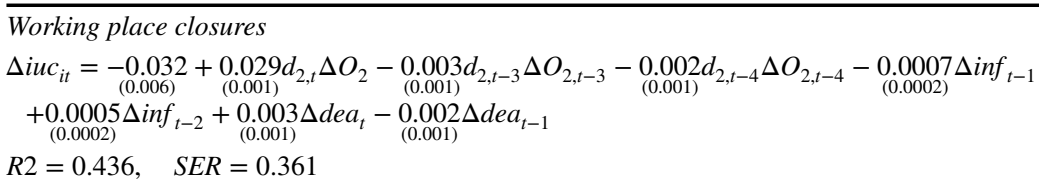

Cancellation of public events

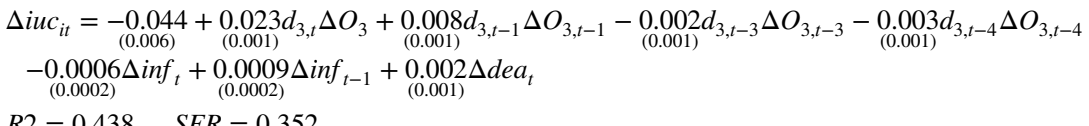

$R 2=0.438, \quad S E R=0.352$

Restrictions on gatherings

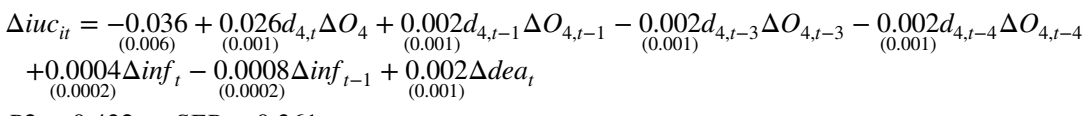

$R 2=0.432, \quad S E R=0.361$

Close of public transport

$\Delta i u c_{i t}=\underset{(0.008)}{0.008}+\underset{(0.002)}{0.027 d_{5, t} \Delta O_{5, t}}-\underset{(0.003)}{0.007 d_{5, t-3} \Delta O_{5, t-3}}-\underset{(0.002)}{0.004 d_{4, t-4} \Delta O_{4, t-4}}$
$+\underset{(0.0002)}{0.0006 \Delta i n f_{t}}-\underset{(0.0002)}{0.0006} \Delta i n f_{t-1}+\underset{(0.001)}{0.003 \Delta d e a_{t}}-\underset{(0.001)}{0.003 \Delta d e a_{t-1}}$

$R 2=0.076, \quad S E R=0.425$

Stay-at-home requirements

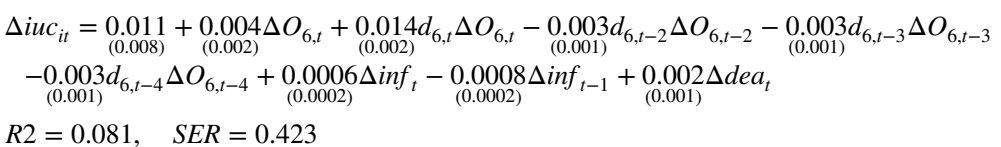

\section{Restrictions on internal movement}

$\Delta i u c_{i t}=\underset{(0.007)}{0.012}+\underset{(0.001)}{0.008} d_{7, t} \Delta O_{7, t}-\underset{(0.001)}{0.004 d_{7, t-4}} \Delta O_{7, t-4}+\underset{(0.0002)}{0.0008} \Delta i n f_{t}-\underset{(0.0002)}{0.0008} \Delta i n f_{t-1}$

$R 2=0.023, \quad S E R=0.433$

International travel controls

$\Delta i u c_{i t}=\underset{(0.008)}{0.009}+\underset{(0.002)}{0.011} d_{8, t} \Delta O_{8, t}+\underset{(0.0002)}{0.0006 \Delta i n f_{t}}-\underset{(0.0002)}{0.0006 \Delta i n f_{t-1}}+\underset{(0.001)}{0.002 \Delta \text { dea }_{t}}-\underset{(0.001)}{0.002 \Delta d e a_{t-1}}$
$R 2=0.001, \quad S E R=0.430$

Panel model with fixed effects for the 51 US states (including District of Columbia) and GLS cross section weights to control for heteroscedasticity, weekly data Feb 12, 2020 to Feb 24, 2021. IUR=Insured unemployment rate, $I U C=$ Initial unemployment claims (in logs). Standard errors in parentheses below regression coefficients. The constant is the average of state level fixed effects. $O$ denotes the specific policy covered by the Oxford index, $d$ is equal to 1 if a policy is tightened and 0 otherwise, inf is the number of new infections and dea the number of deaths. $R 2$ adjusted coefficient of determination and SER the standard error of regression

The overall Oxford stringency index an average of eight different policy interventions, has the strongest impact on labour markets. Applying the same methodology using its individual components show that the results are very robust, and that school and working place closures are most critical for the labour market. The result concerning school closures has important policy implications since it implies that this measure has a high economic cost, while some argue that its effectiveness in limiting contagion is limited (Walsh et al 2021). 
Funding Many thanks to Alexandre Ounnas for support with the data and to CEPS colleagues for comments. This research has received funding from the Horizon 2020 research and innovation programme of the EU under Grant Agreement Nos. 101016233, H2020-SC1-PHE CORONAVIRUS-2020-2-RTD, PERISCOPE (Pan European Response to the Impacts of Covid-19 and future Pandemics and Epidemics).

Data Availability Statement The original data is available from the authors upon request. All data was downloaded from publicly available sources.

\section{References}

Baek CW, McCrory PB, Messer T, Mui P (2020) Unemployment effects of stay-at-home orders. Evidence from high frequency claims data, IRLE Working paper 101-20, forthcoming in Review of Economics and Statistics

Baker SR, Bloom N, Davis SJ, Terry SJ (2020) COVID-induced economic uncertainty, Working paper 26983, National Bureau of Economic Research

Barro RJ, Ursúa JF, Weng J (2020) The coronavirus and the great influenza pandemic: lessons from the "spanish flu" for the coronavirus's potential effects on mortality and economic activity. No. w26866. National Bureau of Economic Research

Bartik AW, Bertrand M, Cullen ZB, Glaeser EL, Luca M, Stanton CT (2020) How are small businesses adjusting to COVID-19? Early evidence from a survey, NBER working paper 26989

Bodenstein M, Corsetti G, Guerrieri L (2020) Social distancing and supply disruptions in a pan-demic, Voxeu.org, 12 June 2020. https://voxeu.org/article/social-distancing-and-supply-disrup-tions-pande mic

Brauner JM, Mindermann S, Sharma M, Stephenson AB, Gavenčiak T, Johnston D, Leech G, Sal-vatier J, Altman G, Norman AJ, Teperowski Monrad J, Besiroglu T, Ge H, Mikulik V, Hartwick MA, The YW, Chindelevitch L, Gal Y, Kulveit J (2020) The effectiveness of eight nonpharmaceutical interventions against COVID-19 in 41 countries, medRxiv. https://doi.org/10.1101/2020.05. 28.201116129

Cajner T, Figura A Price BM, Ratner D, Weingarden A (2020) Reconciling unemployment claims with job losses in the first months of the COVID-19 crisis. FEDS working paper 2020-055. https://doi. org/10.17016/FEDS.2020-055

Capelle-Blancard G, Desroziers A (2020) The stock market and the economy: insights from the COVID19 crisis, VoxEU.org, June

Chudik A, Mohaddes K, Pesaran MH, Raissi M, Rebucci A (2020) A counterfactual economic analysis of Covid-19 using a threshold augmented multi-country model, NBER working paper 27855

Coibion O, Gorodnichenko Y, Weber M (2020) The cost of the COVID-19 crisis: lockdowns, macroeconomic expectations, and consumer spending, NBER working paper 27141

Cortes GM, Forsythe E (2020) The heterogeneous labor market impacts of the COVID-19 pan-demic. Upjohn Institute for Employment Research, Working paper 20-327

Eichenbaum MS, Rebelo S, Trabandt T (2020) The macroeconomics of epidemics, NBER working paper 26882

Forsythe E, Kahn LB, Lange F, Wiczer D (2020) Labor demand in the time of COVID-19. Evidence from vacancy postings and UI claims, Journal of Public Economics 189, Article 104238

Gascon C (2020) COVID-19: which workers face the highest unemployment risk? St Louis Fed on the economy. https://www.stlouisfed.org/on-the-economy/2020/march/covid19-workers-highest-unemp loyment-risk

Getachew Y (2020) Social distancing in macrodynamic models Voxeu.org, 22 September 2020. https:// voxeu.org/article/social-distancing-macrodynamic-models

Gharehgozli O, Nayebvali P, Gharehgozli A, Zamanian Z (2020) Impact of COVID-19 on the economic output of the US outbreak's epicenter. Econ Disasters Clim Change 4:453-479

Guerrieri V, Lorenzoni G, Straub L, Werning I (2020) Macroeconomic implications of COVID-19: can negative supply shocks cause demand shortages? NBER working paper 26918

Gupta S, Montenovo L, Nguyen TD, Rojas FL, Schmutte IM, Kosali IS, Weinberg A, Wing C (2020) Effects of social distancing policy on labor market outcomes, NBER working paper 27280

Hale T, Angrist N, Kira B, Petherick A, Phillips T, Webster S (2020) Variation in government re-sponses to COVID-19, Blavatnik School of Government, Oxford University-working paper-2020/032, May 
Hsiang S, Allen D, Annan-Phan S, Bell K, Bolliger I, Chong T, Druckenmiller H, Huang LY, Hultgren A, Krasovich E, Lau P, Lee J, Rolf E, Tseng J, Wu T (2020) The effect of large-scale anti-contagion policies on the COVID-19 pandemic. Nature 584:262-267

Jena PR, Majhi R, Kalli R, Managi S, Majhi B (2021) Impact of COVID-19 on GDP of major economies: application of the artificial neural network forecaster. Econ Anal Policy 69:324-339

Katafuchi Y, Kurita K, Managi S (2021) COVID-19 with stigma: Theory and evidence from mobility data. Econ Disasters Clim Change 5:71-95

Kok JLC (2020) Short-term trade-off between stringency and economic growth, Covid Economics. Vetted and real time papers 60 .

Laeven, L (2020) COVID-19 and the effects of social distancing on the economy, Voxeu.org, 31 August 2020. https://voxeu.org/article/covid-19-and-effects-social-distancing-economy

Ludvigson SC, Ma S, Ng S (2020) COVID-19 and the macroeconomic effects of costly disasters, NBER working paper no. 26987

Mandel A, Veetil VP (2020) The economic cost of covid lockdowns: an out-of-equilibrium analysis. Econ Disasters Clim Change 4:431-451

Martin A, Markhvida M, Hallegatte S, Walsh B (2020) Socio-economic impacts of COVID-19 on household consumption and poverty. Econ Disasters Clim Change 4:453-479

Montenovo L, Jiang X, Rojas FL, Schmutte IM, Simon K, Weinberg B, Wing C (2020) Determinants of disparities in COVID-19 job losses, NBER working paper 27132

Nakamura H, Managi S (2020) Airport risk of importation and exportation of the COVID-19 pandemic. Transp Policy 96:40-47

Pagano M, Wagner C, Zechner J (2020) COVID-19, asset prices, and the Great Reallocation, VoxEU. org, June

Pozo-Martin F, Weishaar H, Cristea F, Hanefeld J, Schaade L, El Bcheraoui C (2020) Impact of type and timeliness of public health policies on COVID-19 epidemic growth: OECD member states. JanJuly. https://doi.org/10.2139/ssrn.3698853

Rojas FL, Jiang X, Montenovo L, Kosali IS, Weinberg B, Wing C (2020) Is the cure worse than the problem itself? Immediate labor market effects of COVID-19 case rates and school closures in the US, NBER working papers 27127

Walmsley T, Rose A, Wei D (2020) The impacts of the coronavirus on the economy of the United States. Econ Disasters Clim Change. https://doi.org/10.1007/s41885-020-00080-1

Walsh S, Chowdhury A, Russell S, Braithwaite V, Ward J, Waddington C, et al (2021) Do school closures reduce community transmission of COVID-19? A systematic review of observational studies. medRxiv

Publisher's Note Springer Nature remains neutral with regard to jurisdictional claims in published maps and institutional affiliations. 